\title{
COVID-19 outbreak in a personal service setting in Kingston, Ontario, 2020
}

\author{
Anthony Li ${ }^{1,2}$, Stéphanie Parent ${ }^{1,2}$, Azim Kasmani ${ }^{1,3}$, T Hugh Guan $^{1,3}$, Kieran Moore ${ }^{1,3 *}$
}

\begin{abstract}
Background: During the coronavirus disease 2019 (COVID-19) pandemic, Ontario created a three-phase reopening framework for the economy. Outbreaks were expected at each phase. One week after Phase Two of reopening in the provincial public health administration region of Kingston, Frontenac, Lennox and Addington (KFL\&A), a positive case was reported after three weeks of zero new COVID-19 cases. The objective of this report is to describe this COVID-19 outbreak, linked to a personal service setting (PSS), and the public health response to contain the outbreak.
\end{abstract}

Methods: The outbreak investigation included all COVID-19 cases in KFL\&A between June 20, 2020 and July 3, 2020. Public health inspectors and nurses were rapidly deployed to inspect the PSS. A multimodal approach to high-volume testing involved fixed assessment centres, drive-through testing capacity and targeted testing at the outbreak site. Testing was conducted through a real-time polymerase chain reaction assay at the local Public Health Ontario laboratory.

Results: Thirty-seven cases were associated with the outbreak: 38\% through direct PSS exposure; $32 \%$ through household contact; and $30 \%$ through social and workplace contact. A superspreading event contributed to $38 \%$ of total cases. The majority of cases were in the low to mid-quintiles when analyzed for material deprivation. Testing rates increased four-fold compared to the prior baseline weeks in response to media attention and public health messaging, resulting in a low percent positivity.

Conclusion: The interplay of aggressive accessible testing, quick lab turnaround time, contact tracing within 24 hours of positive laboratory results as per provincial standards, frequent public communication, rapid inspections, mandatory self-isolation and face coverings were measures successful in halting the outbreak. Inspections or self-audits should be required at all PSSs prior to reopening and outbreak management must work with PSSs to reduce the possibility of superspreading events.
This work is licensed under a Creative Commons Attribution 4.0 International License.

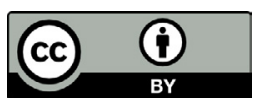

Affiliations

${ }^{1}$ Kingston, Frontenac, Lennox \& Addington (KFL\&A) Public Health, Kingston, ON

${ }^{2}$ School of Medicine, Queen's University, Kingston, ON

${ }^{3}$ Public Health and Preventive Medicine Residency Program, Queen's University, Kingston, ON

*Correspondence:

kieran.moore@kflaph.ca

Suggested citation: Li A, Parent S, Kasmani A, Guan TH, Moore K. COVID-19 outbreak in a personal service setting in Kingston, Ontario, 2020. Can Commun Dis Rep 2021;47(4):216-23.

https://doi.org/10.14745/ccdr.v47i04a06

Keywords: COVID-19, SARS-CoV-2, outbreak, personal service setting, public health, infection prevention and control, case and contact management, superspreading event

\section{Introduction}

Severe acute respiratory syndrome coronavirus 2 (SARS-CoV-2) is an enveloped ribonucleic acid (RNA) beta-coronavirus that causes coronavirus disease (COVID-19), with common symptoms including fever, cough, shortness of breath and fatigue $(1,2)$.

Severe COVID-19 presentations may require intensive care unit admission and may potentially result in death (3). The SARS-CoV-2 is most commonly transmitted through close contact via liquid droplets released by infected individuals and was classed with other novel coronaviruses as a reportable communicable disease in Ontario on January 22, $2020(4,5)$.

While the COVID-19 pandemic has caused 100,000 positive cases and nearly 9,000 deaths in Canada as of July 2020, the Kingston, Frontenac, Lennox and Addington (KFL\&A) region has had a very low community incidence of COVID-19 (6). Although KFL\&A has a population of 209,023 with $20 \%$ of individuals aged 
over 65 years, there have been zero attributed deaths, only one case in a long-term care home and 63 total cases prior to this outbreak (7).

The Ontario government provided a three-phase reopening plan for the economy (8). The KFL\&A region was allowed to move from Phase One to Phase Two on June 12, 2020, which permitted personal service settings (PSSs) such as nail salons, barbershops and tattoo parlours to reopen. Although PSSs were provided with guidance and best practices, inspections were not required prior to reopening. After a three-week period of zero new COVID-19 cases in KFL\&A, a positive case was detected on June 20, 2020 in a hospital staff member, a week after Phase Two of reopening. Two more positive cases were reported three days later, neither of which had any connection to the hospital. Through repeated case interviews and social network analyses, case investigators identified a nail salon as the common source. KFL\&A Public Health sent an inspector and nurse team to investigate infection prevention and control practices (IPAC) and to test workers. Six workers tested positive for COVID-19 and an outbreak was declared on June 25, 2020.

This outbreak demonstrates how PSSs can contribute to disease transmission. Inspections or self-audits with a report back mechanism should be required at all PSSs prior to reopening and should be considered as potential sources of infection during case and contact investigations. A collaborative regional response between the community, local public health agency, laboratory and hospitals running the assessment centres allowed for rapid outbreak management. The objective of this report is to describe the investigation that led to the discovery of the outbreak source and the interventions to contain the outbreak.

\section{Methods}

\section{Detection of the outbreak}

The index case for this outbreak, reported on June 20,2020, was a hospital staff member. Initial investigations did not uncover a source among occupational or household contacts. On June 23, two additional positive cases were identified. None of the three reported each other as contacts nor identified any shared contacts. Upon repeated interviews by case investigators, a common link was discovered: all three cases had visited the same nail salon the week of June 14. KFL\&A Public Health rapidly deployed a public health inspector and nurse team on site to investigate the PSS, test all workers and review IPAC practices. A worker tested positive for COVID-19 within 48 hours, with a total of six workers ultimately testing positive; providing strong evidence that this setting was the outbreak source. On June 25, KFL\&A Public Health officially declared an outbreak to the public and ordered the nail salon to close until further notice.

\section{Case investigation}

Cases were determined by a positive real-time polymerase chain reaction (PCR) assay, according to the provincial ministry definition (9). The internal case definition used by KFL\&A Public Health for this outbreak was a client or a close contact of a positive client of the nail salon. The risk of transmission was hypothesized to have started at the official opening date of the PSS on June 12, 2020. Individuals who tested positive for COVID-19 were contacted within 24 hours of their result by KFL\&A Public Health staff following provincial guidelines (10). The case and contact management investigation included onset date, symptoms, exposure history including travel or positive contacts, risk factors and any close contacts (with level of exposure risk). All cases were actively monitored for a 14-day period following guidance from the Ontario Ministry of Health (11). The estimated average cost per case was $\$ 400$ and required seven staff hours, while the average cost per contact was $\$ 160$ and required three staff hours.

\section{Laboratory investigation}

The Public Health Ontario Laboratory (PHOL) Kingston site conducted real-time PCR testing on specimens and reported cases following the case definition of COVID-19 set by the Ministry of Health. A confirmed case is outlined as "a person with laboratory confirmation of COVID-19 infection using a validated assay, consisting of positive nucleic acid amplification test on at least one specific genome target" (9). The PHOL used the envelope (E) gene assay as the genome target for its laboratory-developed test. The COVID-19 testing turnaround time was $24-48$ hours.

\section{Data analysis}

Microsoft ${ }^{\mathrm{TM}}$ Excel 2016 software was used to create the epidemic curve and descriptive analyses while a social network analysis was conducted using the SocNetV 2.5 tool. Spatial analysis was done with geographical information systems to construct a choropleth map to identify census tracts of high incidence.

Crude attack rates for subsequent generations were calculated using number of confirmed cases per generation and number of susceptible persons (12). Susceptible persons were defined as high-risk contacts, with contacts being counted only once if shared between cases. Swabbing data from the assessment centres and case data from PHOL were used to calculate percent positivity.

The material deprivation score measures the inability of individuals to access basic material needs such as educational attainment or quality housing (13). Deprivation indices were determined for each case to construct an overall material deprivation profile as a proxy for socio-economic status. The material deprivation profile was grouped into quintiles, with higher quintile scores indicating a higher level of deprivation.

\section{Interventions}

The client contact list provided by the nail salon was incomplete, preventing effective contact management from occurring. As such, on June 25, 2020, KFL\&A Public Health released a public announcement urging any clients of this PSS between June 12 
and June 24 to get tested for COVID-19 and self-isolate for 14 days from the date of their last visit. A number of businesses voluntarily closed as a precautionary measure, having employees who had attended the PSS and tested positive.

In addition to the initial nail salon, four employees at two other nail salons eventually tested positive for COVID-19 through contact with staff at the first salon. The KFL\&A Public Health issued a media release requesting that all clients who frequented these two PSSs self-isolate and be tested. Both salons were closed until further notice. Over 500 customers visited the initial nail salon associated with the outbreak between June 12 and June 20, all of whom were requested to self-isolate and get tested. An additional 180 close contacts of the positive cases were also requested to self-isolate and obtain testing.

To minimize the risks of additional outbreaks in public settings, the Medical Officer of Health of KFL\&A issued an order on June 27, 2020 under Section 22 of the Ontario Health Protection and Promotion Act prohibiting individuals from entering and remaining inside indoor commercial establishments if not wearing a face covering and also ensuring the availability of alcohol-based hand rubs at all entrances and exits. Furthermore, on June 30, KFL\&A Public Health mandated self-isolation and quarantine for COVID-19 cases or close contacts of a positive case. An advisory was also released requiring all PSSs to complete a checklist developed to ensure PSS compliance with IPAC regulations (14).

\section{Results}

There were 37 cases of COVID-19 associated with the outbreak between June 20 and July 3 (Figure 1). The majority of cases (65\%) were female, and the average age was 38.6 years old, with a range of 11 months to 69 years old. The cases had various occupations, including in healthcare, education, construction, restaurant, retail and corrections. Of the 37 cases, 14 (38\%) were from direct exposure through the PSS, 12 (32\%) were household contacts with another case, and the remaining 11 (30\%) were social and workplace contacts with a case (Figure 2). One PSS client alone infected six people at a social gathering and two coworkers.

Once KFL\&A Public Health identified the nail salon as the common link between the initial three cases, a public health inspector and nurse team were rapidly deployed on site to investigate. Considerable deficiencies in IPAC practices were noted. Staff were observed having inadequate hand hygiene, washing only for several seconds and without the use of soap. Staff were not screened for COVID-19 symptoms and showed up to work with symptoms. Improper wearing of face masks was also observed by both clients and staff, including hanging under the chin, exposing the nose, or being removed when using a phone. Workstations and equipment were not cleaned prior
Figure 1: Epidemic curve for the COVID-19 outbreak in a Kingston, Frontenac, Lennox \& Addington personal service setting outbreak, $2020(n=37)$

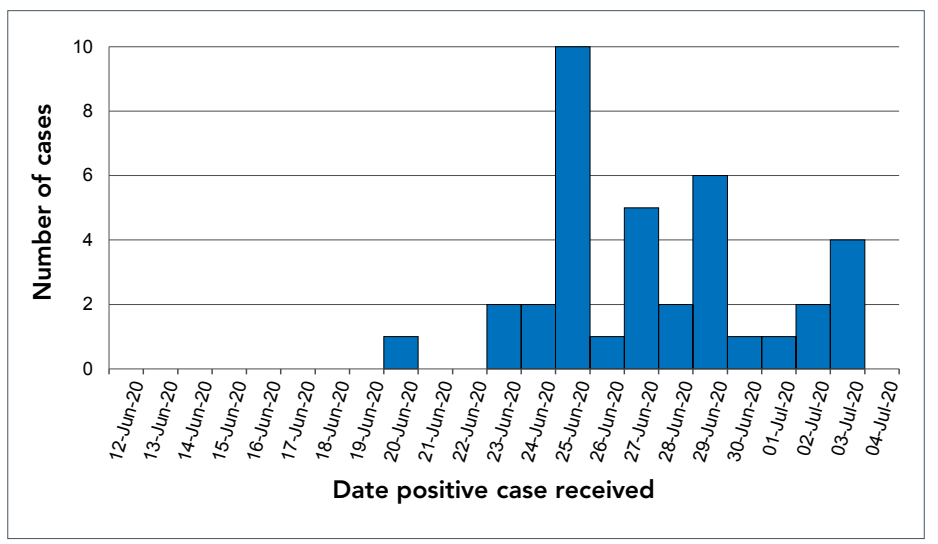

Figure 2: Social network analysis for COVID-19 cases in the Kingston, Frontenac, Lennox \& Addington personal service setting outbreak, 2020

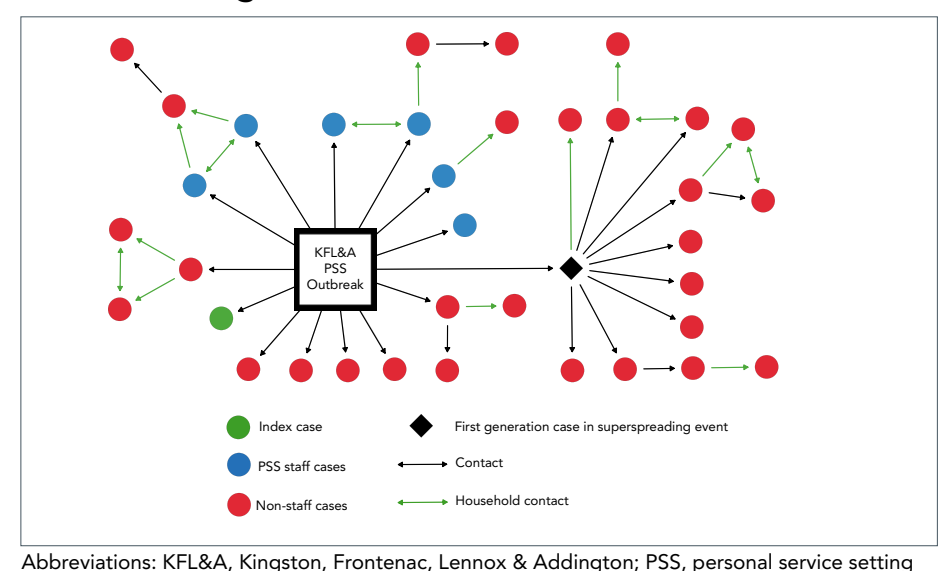

to disinfecting, and high-touch surfaces were only cleaned and disinfected once a day. Furthermore, handwritten records of client names and phone numbers were often incomplete and/or illegible. Six workers eventually tested positive for COVID-19.

Seven (19\%) of the 37 cases were asymptomatic at the time of diagnosis. Three of the seven asymptomatic cases never went on to develop symptoms of COVID-19. One case of transmission of COVID-19 was identified from a true asymptomatic case. Only one case associated with the outbreak was hospitalized. This individual had comorbidities, requiring an eight-day admission to hospital and five-day stay in the intensive care unit. No deaths were associated with this outbreak.

Choropleth map profiling indicated higher case counts closer to the outbreak source and relatively even spatial distribution across census tracts (Figure 3 ). The material deprivation profile of cases indicated that $54 \%$ of cases were in the low to mid-quintiles of material deprivation, associated with areas of higher socio-economic status, whereas $38 \%$ of cases were in the 
top quintiles of material deprivation, associated with areas of lower socio-economic status (Figure 4). No data was available for the remaining $8 \%$ of cases.

Figure 3: Choropleth map for COVID-19 cases associated with the Kingston, Frontenac, Lennox \& Addington personal service setting outbreak, 2020

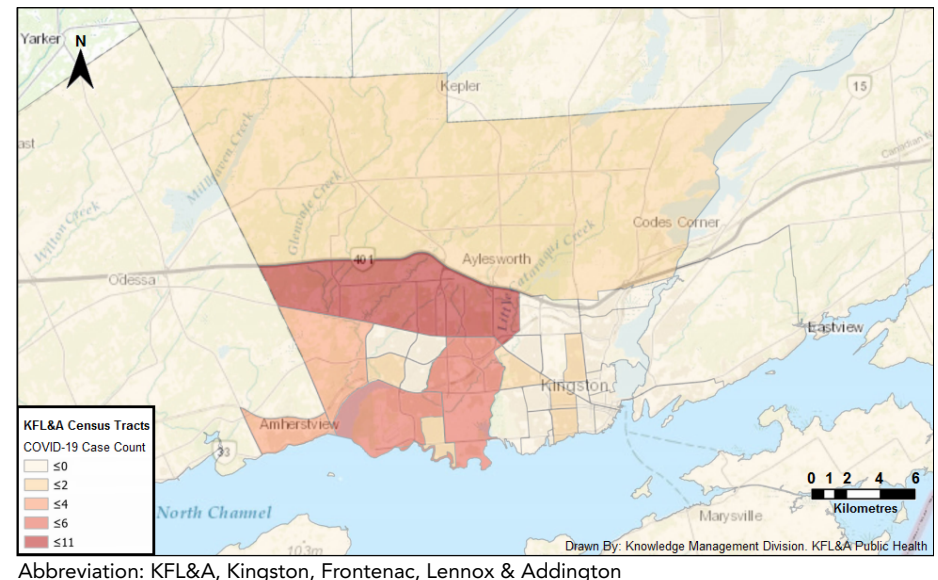

Figure 4: Material deprivation profile of cases associated with the Kingston, Frontenac, Lennox \& Addington personal service setting outbreak, 2020

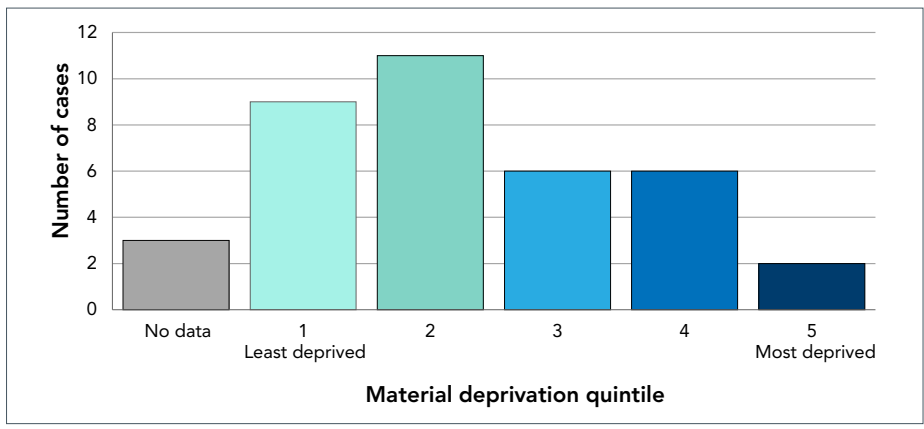

Four generations of transmission were identified (Figure 5). There were 14 cases in the first generation, with an estimated 500 patrons and staff who were potentially exposed to COVID-19. Due to incomplete client records, an estimate was needed and was calculated using the likely number of clients serviced daily based on salon capacity during the 13 days it was open. As such, the attack rate for the first generation was $2.8 \%$. The second generation of 16 cases and 101 contacts had an attack rate of $15.8 \%$. The third generation of six cases and 49 contacts had an attack rate of $12.2 \%$. The fourth generation of one case and 14 contacts had an attack rate of $7.4 \%$. Crude estimated total costs for the case and contact management of this outbreak investigation were approximately $\$ 41,040$ and 751 staff hours.

The KFL\&A Public Health had a multimodal approach to swabbing, including fixed assessment centres, drive-through testing capacity and targeted testing at the outbreak site.
Figure 5: COVID-19 cases and contacts per generation in the Kingston, Frontenac, Lennox \& Addington personal service setting outbreak, 2020

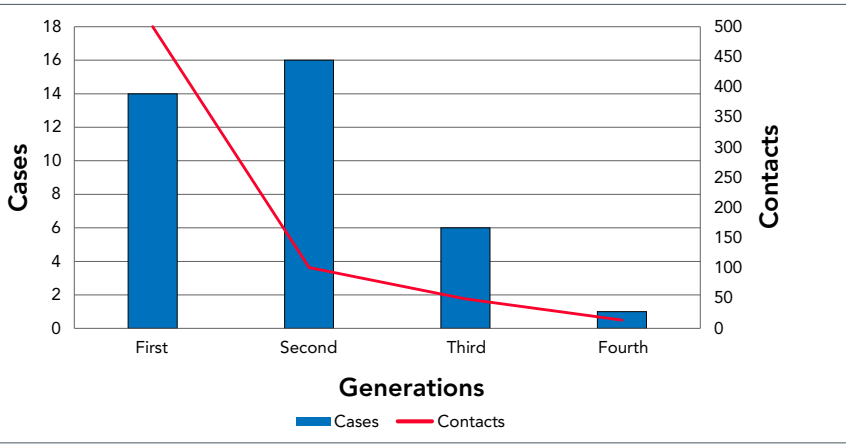

Testing rates between June 20 and July 5 were high in response to media attention and messaging from KFL\&A Public Health and there was approximately a four-fold increase in testing during the outbreak compared to the prior baseline weeks (Figure 6). In addition, the cumulative number of tests completed in the KFL\&A region from the start of this outbreak surpassed 10,000 by July 7 . Percent positivity remained low and reached a peak of $0.61 \%$ on June 29 (Figure 7 ).

Figure 6: Number of patients swabbed by day in assessment centres

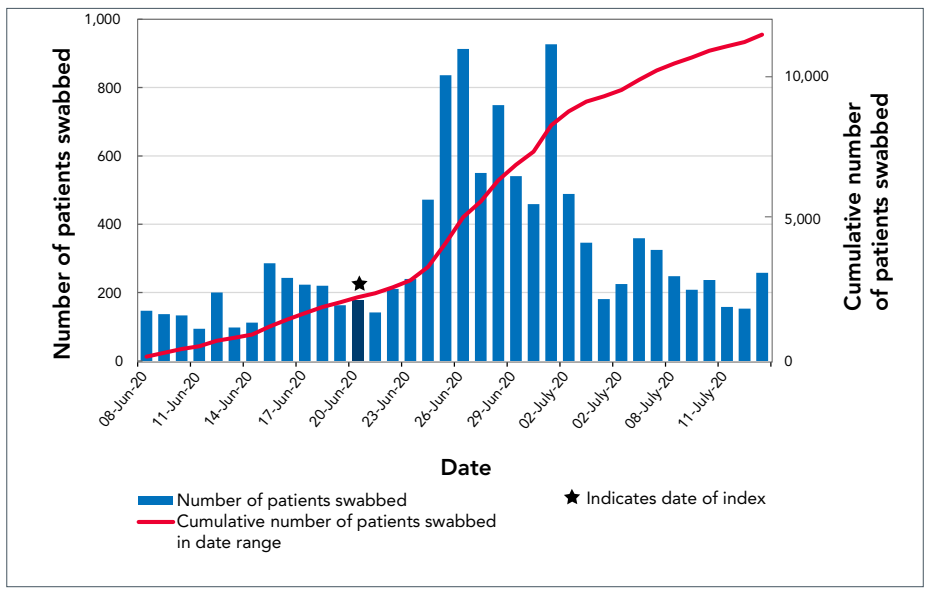

Figure 7: Percent positivity 7-day moving average of COVID-19 tests

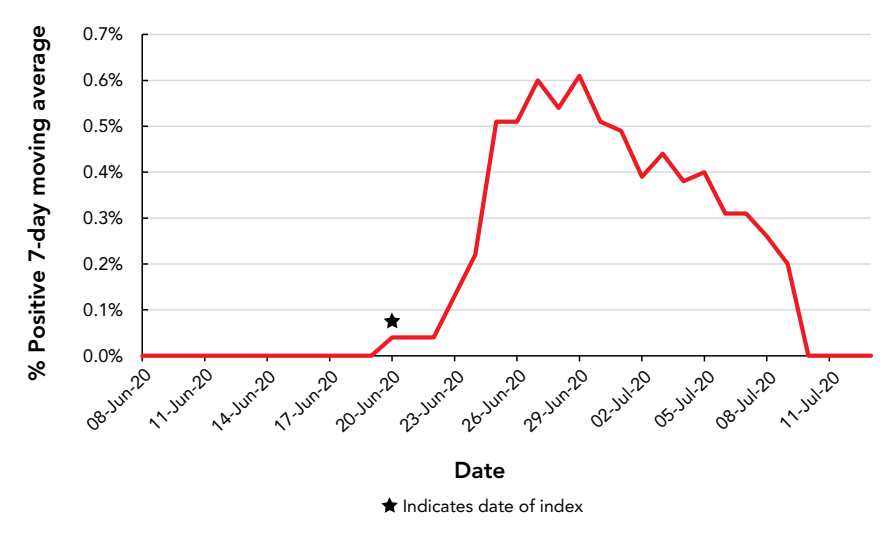




\section{Discussion}

Prior to this PSS outbreak, KFL\&A had one of the lowest case rates in Ontario with 29.1 cumulative cases per 100,000 population (15). After three weeks of zero new COVID-19 cases in KFL\&A, the detection of an outbreak one week after Phase Two of reopening indicated deficiencies in adherence to government recommendations and best practices.

Transmission of disease is facilitated in a PSS due to difficulties in maintaining physical distancing while receiving a service. Staff can come into close contact with dozens of clients each day, and any reuse of inadequately sterilized equipment exacerbates the situation. The transmission of mycobacteria, hepatitis $B$ virus and hepatitis $C$ virus has been well documented in PSSs (16-19). A combination of factors contributed to this PSS outbreak. Insufficient hand hygiene, improper face mask usage and staff working while symptomatic allowed for the transmission of COVID-19. Handwashing for only several seconds without soap usage and face mask wearing that exposed the mouth or nose indicated poor IPAC practices, in addition to the deficiencies in cleaning of workstations and equipment. The effectiveness of good adherence to IPAC has been seen in a PSS in Missouri, United States where two infectious (COVID-19) symptomatic hair stylists did not transmit to any of their 139 exposed clients, as all staff and clients wore face masks properly and followed robust hand hygiene practices (20). An inspection of adherence to best IPAC practices prior to reopening are essential to preventing future outbreaks. A self-audit of IPAC practices with a report back mechanism to public health could be another approach.

The 37 cases of COVID-19 linked to the nail salon required an aggressive local public health response to contain the spread of the virus, including early outbreak source identification, broad community awareness, high-volume testing initiatives and identification of subsequent cases. This permitted rapid contact tracing within the 24-hour provincial guidelines and allowed for isolation of cases and contacts to contain the outbreak. The effectiveness could be seen by the decrease in attack rates after the second generation, indicating that cases and contacts were isolating and preventing further transmission (Figure 5).

Seven (19\%) cases were asymptomatic at the time of diagnosis, and three (8\%) remained asymptomatic. This falls within the lower end of the $18 \%-57 \%$ range of asymptomatic rates previously reported in the literature (21-24). These cases were found due to high-volume swabbing and testing rates, resulting in a low percent positivity throughout the outbreak. Early detection of asymptomatic cases allowed for timely isolation preventing further transmission (25). Individuals who are asymptomatic are difficult to trace, less likely to self-isolate, and more likely to engage in social behaviours (26). Our outbreak provides support that initially asymptomatic cases often develop symptoms and become pre-symptomatic cases. More evidence is required for a better understanding of the prevalence and role of true asymptomatic transmission compared to pre-symptomatic transmission in COVID-19.

Secondary transmission to people who did not attend the nail salon occurred mainly through household contact. In total, 12 (32\%) cases were household contacts with another case in the outbreak. Previous reports have shown household secondary attack rates for COVID-19 of $11.2 \%-35 \%$ (27-31). This type of transmission was expected, having been described with SARS-CoV, Middle East respiratory syndrome (MERS) and influenza (32-34). People living in the same household generally practice activities that facilitate infection via droplets, such as intimacy and sharing food and drinks. Although it may be challenging to interrupt transmission of SARS-CoV-2 between household contacts, management of this outbreak showed that limiting spread outside of the household was made easier by identifying cases early in the course of illness and isolating them along with close contacts.

Superspreading events occur when a case spreads disease far more widely than others. They have been seen worldwide including at a choir in the United States, a nightclub in South Korea and a blessing ceremony in China (35-37). A superspreading event was noted in this PSS outbreak: one client was responsible for 14 (38\%) cases, none of whom attended the nail salon. Of these, two were workplace contacts while six attended a social event with the first-generation case, subsequently transmitting the virus to their own contacts. Contact tracing for this cluster was very challenging: a number of contacts were not identified during the intake interview of the initial case; however, individuals later testing positive subsequently identified having close contact with the initial case. Superspreading events have played a large role in COVID-19 transmission, with a recent modelling study proposing that an effective way to control the epidemic was limiting random contacts outside of workplace and household environments (35). This supports the provincial guidelines at the outbreak onset of maintaining a social circle of up to 10 people (38). The client in the KFL\&A superspreading event had a social circle much larger than 10 , highlighting the importance of maintaining small social circles to avoid superspreading events.

The mass quarantine of hundreds of individuals had widespread social, health and economic consequences. The day after the outbreak was announced, hundreds of people lined outside the assessment centre; some waiting for hours to be tested. Businesses closed due to the necessity of quarantining workers, and the community was hesitant to access businesses that remained open. In Ontario, regions with the lowest socio-economic status have carried the largest burden of COVID-19 (39); however, the majority of cases associated to this outbreak were located in geographical areas associated with higher socio-economic status. It is possible that the greater 
impact on individuals of higher socio-economic status was due to their increased likelihood of being able to purchase aesthetic services. The choropleth map indicated no major associations beyond proximity to the outbreak source.

\section{Limitations}

There are several limitations to this report. Data on symptoms and close contacts was self-reported and vulnerable to social desirability and recall bias. With media coverage and stigma surrounding social activities, respondents may have provided reports that were deemed more socially acceptable; a common trend in case and contact management (40-42). Some of the data may be incomplete due to resource and data management system limitations. The assessment centres, PHOL, local public health agency and hospitals use different electronic information systems, which are not integrated. In addition, the sudden large increase in cases and contacts partially overwhelmed the assessment centres leading to potential data quality issues. Also, it is not possible to determine a causal relationship between any single initiative and its effect on controlling the outbreak as all initiatives likely worked in conjunction to limit the outbreak. Furthermore, inferences based on geographical indicators may be flawed and not apply at the individual level leading to the ecological fallacy. Finally, data was only collected on cases and contacts within the KFL\&A jurisdiction, with extra-jurisdictional individuals being referred to their respective local public health agency. As such, they may not be captured, resulting in underreporting. Despite these limitations, this report adds to the literature by reviewing a COVID-19 PSS outbreak and describing the subsequent initiatives that led to its interruption in a medium-sized local public health agency in Ontario.

\section{Conclusion}

Overall, KFL\&A Public Health, PHOL and the hospitals running the assessment centres were able to contain and manage a COVID-19 outbreak in a PSS with continuous public communications, rapid inspections, aggressive testing, public health orders, short testing turnaround times and thorough case and contact management occurring within 24 hours of positive laboratory results. The KFL\&A community also played a crucial role in protecting one another by getting tested and adhering to KFL\&A Public Health's orders to self-isolate and wear face coverings in indoor public spaces. These actions can inform decision-making by other jurisdictions that may be dealing with similar future outbreaks. A collective collaborative approach is needed in an outbreak, as all members of the community must work together to limit the spread of disease.

\section{Authors' statement}

$A L$ and $S P$ - Writing-original draft

$\mathrm{AL}$ - Data visualization, analysis and interpretation

AK and THG - Epidemiologic and environmental investigations and response and provided feedback

$\mathrm{KM}$ - Oversaw the epidemiologic and environmental investigations, provided feedback, supervised the work
All authors contributed to the conceptualization of the manuscript.

The content and view expressed in this article are those of the authors and do not necessarily reflect those of the Government of Canada.

\section{Competing interests}

None.

\section{Acknowledgements}

The authors would like to thank all the staff at KFL\&A Public Health who contributed to the investigation of this outbreak, including the investigators, nurses, case and contact management team and assessment centre personnel, as well as the staff at the Kingston Health Sciences Centre, the Lennox and Addington County General Hospital and the local Public Health Ontario Laboratory. The authors would also like to thank the following individuals for their contributions to this report: J Sousa, A Kern, D Rines, C Tran, B Mosely, A van Dijk and S Biro. Finally, the authors would like to acknowledge all the individuals and organizations affected by this outbreak and the COVID-19 pandemic.

\section{Funding}

No external funding was received.

\section{References}

1. World Health Organization. Coronavirus disease (COVID-19) pandemic. WHO; 2019 (accessed 2020-07-24). https://www. who.int/emergencies/diseases/novel-coronavirus-2019

2. Centers for Disease Control and Prevention. Coronavirus Disease 2019 (COVID-19) - Symptoms. Centers for Disease Control and Prevention. CDC; 2020 (updated 2020-12; accessed 2020-08-13). https://www.cdc.gov/ coronavirus/2019-ncov/symptoms-testing/symptoms.html

3. CDC COVID-19 Response Team. COVID-19 Response Team. Severe outcomes among patients with coronavirus disease 2019 (COVID-19)_United States, February 12-March 16, 2020. MMWR Morb Mortal Wkly Rep 2020;69(12):343-6. DOI PubMed

4. Hui DS, I Azhar E, Madani TA, Ntoumi F, Kock R, Dar O, Ippolito G, Mchugh TD, Memish ZA, Drosten C, Zumla A, Petersen E. The continuing 2019-nCoV epidemic threat of novel coronaviruses to global health - The latest 2019 novel coronavirus outbreak in Wuhan, China. Int J Infect Dis 2020;91:264-6. DOI PubMed 
5. Government of Ontario. O. Reg. 135/18: Designation of diseases. https://www.ontario.ca/laws/regulation/180135

6. Public Health Agency of Canada. Coronavirus disease (COVID-19). Ottawa (ON): PHAC; (updated 2020-02; accessed 2020-07-24). https://www.canada.ca/en/ public-health/services/diseases/coronavirus-diseasecovid-19.html

7. Government of Ontario. Ministry of Finance. Ontario population projections, 2018-2046. Government of Ontario; (updated 2020-10; accessed 2020-08-11). https://www.fin. gov.on.ca/en/economy/demographics/projections/

8. Government of Ontario. A framework for reopening our province. Government of Ontario; (updated 2020-11; accessed 2020-08-11). https://www.ontario.ca/page/ framework-reopening-our-province

9. Government of Ontario. Ministry of Health. COVID-19 guidance for the health sector. Government of Ontario; (updated 2020-02; accessed 2020-07-24). http://www.health. gov.on.ca/en/pro/programs/publichealth/coronavirus/2019_ guidance.aspx

10. Government of Ontario. Ministry of Health. Management of cases and contacts of COVID-19 in Ontario; version 11.0. Government of Ontario; (updated 2020-01; accessed 2020-07-30). http://www.health.gov.on.ca/en/pro/ programs/publichealth/coronavirus/docs/contact_mngmt/ management_cases_contacts.pdf

11. Government of Ontario. Ministry of Health. COVID-19 provincial testing guidance update version 9.0. Government of Ontario; (accessed 2020-07-30). http://www.health. gov.on.ca/en/pro/programs/publichealth/coronavirus/ docs/2019_testing_guidance.pdf

12. Huang YT, Tu YK, Lai PC. Estimation of the secondary attack rate of COVID-19 using proportional meta-analysis of nationwide contact tracing data in Taiwan. J Microbiol Immunol Infect. Infect 2021;54(1):89-92. DOI PubMed

13. Public Health Ontario. Ontario marginalization index (ON-Marg). Toronto (ON); PHO; (updated 2018-10; accessed 2020-07-24). https://www.publichealthontario.ca/en/Data and Analysis/Health Equity/Ontario Marginalization Index

14. Kingston F; Lennox and Addington Public Health. Nails and aesthetic services COVID-19 prevention checklist. KFLAPH; 2020 (accessed 2020-08-14). https://www.kflaph.ca/en/ partners-and-professionals/resources/Coronavirus/2020-0623-Nails-Aesthetic-Services-COVID-19-Prevention-Checklist. pdf

15. Government of Ontario. COVID-19: Epidemiologic summaries from Public Health Ontario. Toronto (ON): Government of Ontario; (updated 2021-02; accessed 2020-07-24). https://covid-19.ontario.ca/covid19-epidemiologic-summaries-public-health-ontario
16. Pavlik I, Falkinham JO, Kazda J. Environments providing favourable conditions for the multiplication and transmission of mycobacteria. In: Kazka J, Pavlik I, Falkinham JO, Hruska K. The Ecology of Mycobacteria: Impact on Animal's and Human's Health. Dordrecht: Springer Netherlands; 2009. p. 89-197 (accessed 2020-08-06). http://link.springer. com/10.1007/978-1-4020-9413-2_5

17. Koroglu M, Demiray T, Ozbek A, Guclu E, Karabay O, Altindis M, Durmaz R. Nail scissors and fingernails as reservoirs of hepatitis $B$ virus DNA: role of nail scissors in household transmission of hepatitis $B$ virus. Am J Infect Control 2018;46(7):793-7. DOI PubMed

18. Yang J, Hall K, Nuriddin A, Woolard D. Risk for hepatitis B and $C$ virus transmission in nail salons and barbershops and state regulatory requirements to prevent such transmission in the United States. J Public Health Manag Pract 2014;20(6):E20-30. DOI PubMed

19. Barn P, Chen T. A narrative review of infections associated with personal service establishments Part I: aesthetics. Environ Health Rev. 2012;55(1):19-26. DOI

20. Hendrix MJ, Walde C, Findley K, Trotman R. Absence of apparent transmission of SARS-CoV-2 from two stylists after exposure at a hair salon with a universal face covering policy-Springfield, Missouri, May 2020. MMWR Morb Mortal Wkly Rep 2020;69(28):930-2. DOI PubMed

21. Mizumoto K, Kagaya K, Zarebski A, Chowell G. Estimating the asymptomatic proportion of coronavirus disease 2019 (COVID-19) cases on board the Diamond Princess cruise ship, Yokohama, Japan, 2020. Euro Surveill 2020;25(10):2000180. DOl PubMed

22. Nishiura $H$, Kobayashi $T$, Miyama $T$, Suzuki A, Jung SM, Hayashi K, Kinoshita R, Yang Y, Yuan B, Akhmetzhanov AR, Linton NM. Estimation of the asymptomatic ratio of novel coronavirus infections (COVID-19). Int J Infect Dis 2020;94:154-5. DOI PubMed

23. Rivett L, Sridhar S, Sparkes D, Routledge M, Jones NK, Forrest S, Young J, Pereira-Dias J, Hamilton WL, Ferris $M$, Torok ME, Meredith L, Curran MD, Fuller S, Chaudhry A, Shaw A, Samworth RJ, Bradley JR, Dougan G, Smith KG, Lehner PJ, Matheson NJ, Wright G, Goodfellow IG, Baker S, Weekes MP; CITIID-NIHR COVID-19 BioResource Collaboration. Screening of healthcare workers for SARS-CoV-2 highlights the role of asymptomatic carriage in COVID-19 transmission. eLife 2020;9:e58728. DOI PubMed

24. Arons MM, Hatfield KM, Reddy SC, Kimball A, James A, Jacobs JR, Taylor J, Spicer K, Bardossy AC, Oakley LP, Tanwar S, Dyal JW, Harney J, Chisty Z, Bell JM, Methner M, Paul $P$, Carlson CM, McLaughlin HP, Thornburg N, Tong S, Tamin A, Tao Y, Uehara A, Harcourt J, Clark S, Brostrom-Smith C, Page LC, Kay M, Lewis J, Montgomery $P$, Stone ND, Clark TA, Honein MA, Duchin JS, Jernigan JA; Public Health-Seattle and King County and CDC COVID-19 Investigation Team. Presymptomatic SARS-CoV-2 infections and transmission in a skilled nursing facility. N Engl J Med 2020;382(22):2081-90. DOI PubMed 
25. Furukawa NW, Brooks JT, Sobel J. Evidence supporting transmission of severe acute respiratory syndrome coronavirus 2 while presymptomatic or asymptomatic. Emerg Infect Dis 2020;26(7):e201595. DOI PubMed

26. Park SW, Cornforth DM, Dushoff J, Weitz JS. The time scale of asymptomatic transmission affects estimates of epidemic potential in the COVID-19 outbreak. Epidemics 2020;31:100392. DOI PubMed

27. Wang Z, Ma W, Zheng X, Wu G, Zhang R. Household transmission of SARS-CoV-2. J Infect 2020;81(1):179-82. DOI PubMed

28. Jing $Q L$, Liu MJ, Zhang ZB, Fang LQ, Yuan J, Zhang AR, Dean NE, Luo L, Ma MM, Longini I, Kenah E, Lu Y, Ma Y, Jalali N, Yang ZC, Yang Y. Household secondary attack rate of COVID-19 and associated determinants in Guangzhou, China: a retrospective cohort study. Lancet Infect Dis 2020;20(10):1141-50. DOI PubMed

29. Li W, Zhang B, Lu J, Liu S, Chang Z, Peng C, Liu X, Zhang P, Ling $Y$, Tao K, Chen J. Characteristics of household transmission of COVID-19. Clin Infect Dis 2020;71(8):1943-6. DOI PubMed

30. Bi Q, Wu Y, Mei S, Ye C, Zou X, Zhang Z, Liu X, Wei L, Truelove SA, Zhang T, Gao W, Cheng C, Tang X, Wu X, Wu Y, Sun B, Huang S, Sun Y, Zhang J, Ma T, Lessler J, Feng T. Epidemiology and transmission of COVID-19 in 391 cases and 1286 of their close contacts in Shenzhen, China: a retrospective cohort study. Lancet Infect Dis 2020;20(8):911-9. DOl PubMed

31. Grijalva CG, Rolfes MA, Zhu Y, McLean $H Q$, Hanson KE, Belongia EA, Halasa NB, Kim A, Reed C, Fry AM, Talbot HK. Transmission of SARS-COV-2 Infections in Households Tennessee and Wisconsin, April-September 2020. MMWR Morb Mortal Wkly Rep 2020;69(44):1631-4. DOI PubMed

32. Lau JT, Lau M, Kim JH, Tsui HY, Tsang T, Wong TW. Probable secondary infections in households of SARS patients in Hong Kong. Emerg Infect Dis 2004;10(2):236-43. DOI PubMed

33. Drosten C, Meyer B, Müller MA, Corman VM, Al-Masri M, Hossain R, Madani H, Sieberg A, Bosch BJ, Lattwein E, Alhakeem RF, Assiri AM, Hajomar W, Albarrak AM, Al-Tawfiq JA, Zumla Al, Memish ZA. Transmission of MERS-coronavirus in household contacts. N Engl J Med 2014;371(9):828-35. DOI PubMed
34. Tsang TK, Lau LL, Cauchemez S, Cowling BJ. Household transmission of influenza virus. Trends Microbiol 2016;24(2):123-33. DOI PubMed

35. Sneppen K, Taylor RJ, Simonsen L. Impact of superspreaders on dissemination and mitigation of COVID-19. medRxiv. 2020.05.17.20104745. DOI

36. Hamner L, Dubbel P, Capron I, Ross A, Jordan A, Lee J, Lynn J, Ball A, Narwal S, Russell S, Patrick D, Leibrand H. High SARS-CoV-2 attack rate following exposure at a choir practice-Skagit County, Washington, March 2020. MMWR Morb Mortal Wkly Rep 2020;69(19):606-10. DOI PubMed

37. Lin J, Yan K, Zhang J, Cai T, Zheng J. A super-spreader of COVID-19 in Ningbo city in China. J Infect Public Health 2020;13(7):935-7. DOI PubMed

38. Leng T, White C, Hilton J, Kucharski AJ, Pellis L, Stage H, Davies N, CMMID-Covid-19 WG, Keeling MJ, Flasche S. The effectiveness of social bubbles as part of a Covid-19 lockdown exit strategy, a modelling study. medRxiv. 2020.06.05.20123448. DOI

39. Public Health Ontario. Enhanced Epidemiological Summary: COVID-19 in Ontario - A Focus on Material Deprivation. Toronto (ON); PHO; 2020 (accessed 2020-08-24). https:// www.publichealthontario.ca/-/media/documents/ncov/ epi/2020/06/covid-19-epi-material-deprivation.pdf?la=en

40. Veličko I, Ploner A, Sparén P, Marions L, Herrmann B, Kühlmann-Berenzon S. Sexual and testing behaviour associated with Chlamydia trachomatis infection: a cohort study in an STI clinic in Sweden. BMJ Open 2016;6(8):e011312. DOI PubMed

41. Chesang K, Hornston S, Muhenje O, Saliku T, Mirjahangir J, Viitanen A, Musyoki H, Awuor C, Githuka G, Bock N. Healthcare provider perspectives on managing sexually transmitted infections in HIV care settings in Kenya: A qualitative thematic analysis. PLoS Med 2017;14(12):e1002480. DOI PubMed

42. von Wyl V, Bonhoeffer S, Bugnion E, Puhan MA, Salathé M, Stadler T, Troncoso C, Vayena E, Low N. A research agenda for digital proximity tracing apps. Swiss Med Wkly 2020;150(2930):w20324. DOI PubMed 